\title{
PENGARUH ARUS LAUT TERHADAP SEDIMENTASI DI PANTAI BARANE KABUPATEN MAJENE
}

\author{
*Yusman \\ Prodi Teknik Sipil Fakultas Teknik Universitas Sulawesi Barat \\ *yusman@unsulbar.ac.id
}

\begin{abstract}
Abstrak
Sedimentasi adalah pengendapan material batuan yang telah diangkut oleh air atau angin. Majene adalah salah satu daerah di Indonesia yang sebagian besar merupakan wilayah pesisir sehingga perlu dilakukan penelitian tentang laju sedimentasi. Penentuan laju sedimen menggunakan perangkat rakitan yang terbuat dari besi $4 \mathrm{~m}$ dan pipa 2 inch sepanjang $25 \mathrm{~cm}$ yang diikat ke besi. Lokasi pengukuran terdiri dari 3 lokasi. Lokasi pertama terletak di ujung barat pantai barane, lokasi kedua terletak di tengah dan lokasi ketiga terletak di ujung timur pantai barane yang dekat dengan muara sungai. Pengukuran ketinggian sedimen dalam pipa dilakukan setiap minggu untuk setiap lokasi selama 3 kali pengukuran. Dari hasil penelitian, laju sedimentasi di lokasi 1 berkisar antara 14,788.36-23.238,85 $\mathrm{cm}^{3} /$ tahun dengan sedimentasi rata-rata $18.661 .5 \mathrm{~cm}^{3} /$ tahun. Laju sedimentasi untuk lokasi 2 berkisar antara $12.675 .73-21.654 .38 \mathrm{~cm}^{3} /$ tahun dengan sedimentasi rata-rata $16.724 .92 \mathrm{~cm}^{3} /$ tahun. Laju sedimentasi untuk lokasi 3 berkisar antara $13732.04-16900.98 \mathrm{~cm}^{3} /$ tahun dengan sedimentasi rata-rata $15.562 .98 \mathrm{~cm}^{3} /$ tahun. Arus laut membawa sedimen ke arah ujung barat pantai barane sehingga laju sedimentasi terbesar terdapat di lokasi pertama.
\end{abstract}

Kata Kunci: Sedimentasi, Arus Laut, Pantai Barane.

\begin{abstract}
Abstrct
Sedimentation is the deposition of rock material that has been transported by water or wind. Majene is one of the areas in Indonesia which is mostly a coastal area so it is necessary to research the sedimentation rate. The sediment rate was determined using an assembled device made of $4 \mathrm{~m}$ iron and a $25 \mathrm{~cm}$ long 2-inch pipe tied to the iron. The measurement location consists of 3 locations. The first location is located at the western end of Barane beach, the second location is in the middle and the third location is located at the eastern end of Barane Beach which is close to the river mouth. The sediment height measurement in the pipe was carried out every week for each location for 3 measurements. From the research results, the sedimentation rate at location 1 ranged from 14,788.36-23,238.85 $\mathrm{cm}^{3} /$ year with average sedimentation of 18,661.5 $\mathrm{cm}^{3} /$ year. The sedimentation rate for location 2 ranged from 12,675.73-21,654.38 $\mathrm{cm}^{3} / y e a r$ with an average sedimentation of $16,724.92 \mathrm{~cm}^{3} /$ year. The sedimentation rate for location 3 ranges from $13732.04-$ $16900.98 \mathrm{~cm}^{3} /$ year with average sedimentation of $15,562.98 \mathrm{~cm}^{3} /$ year. Ocean currents carry sediment towards the western end of the Barane coast so that the largest sedimentation rate is at the first location.
\end{abstract}

Keyword: Sedimentation, Ocean Currents, Barane Beach.

\section{PENDAHULAN}

Kabupaten majene merupakan daerah yang terdiri dari pengunungan dan wilayah pesisir dan terdiri dari daerah aliran sungai (DAS), salah satunya adalah sungai mandar yang bermuara di pantai barane Kabupten Majene. Pada saat musim hujan sungai mandar akan mengalami peningkatan debit air sehingga meluap dan mengakibatkan terjadinya banjir yang mengangkut material organik maupun anorganik ke muara sungai, sehingga perairan mengalami kekeruhan kemudian mengendap menjadi sedimentasi di pantai [8]. Permasalahan mendasar pada wilayah pesisir adalah pencemaran yang disebabkan oleh masuknya partikel 
bahan organik dan anorganik yang dibawa aliran sungai dan akhirnya mengendap di muara sungai yang terletak di pesisir pantai [5].

Sedimentasi adalah peristiwa pengendapan material batuan yang telah diangkut oleh tenaga air atau angin. Pada saat pengikisan terjadi, air membawa batuan mengalir ke sungai, danau, dan akhirnya sampai di laut. Pada saat kekuatan pengangkutannya berkurang atau habis, batuan diendapkan di daerah aliran air. Karena itu pengendapan ini bisa terjadi di sungai, danau, dan di laut. Batuan hasil pelapukan secara berangsur diangkut ke tempat lain oleh tenaga air, angin. Air mengalir di permukaan tanah atau sungai membawa batuan halus baik terapung, melayang atau digeser di dasar sungai menuju tempat yang lebih rendah. Hembusan angin juga bisa mengangkat debu, pasir, bahkan bahan material yang lebih besar. Makin kuat hembusan itu, makin besar pula daya angkutnya. Di padang pasir misalnya, timbunan pasir yang luas dapat dihembuskan angin dan berpindah ke tempat lain [4].

Kekeruhan yang tinggi akibat proses sedimentasi mengakibatkan penurunan penetrasi cahaya sehingga akan mengurangi fotosisintesis dari zooxanthellae dan secara tidak langsung mempengaruhi terumbu karang [2]. Sedimen di perairan terumbu karang dapat mempengaruhi komunitas ekologi dan komposisi terumbu karang [6]. Pada tingkat komunitas dan populasi, peningkatan sedimentasi dapat menghalangi rekrutmen populasi, menyebabkan perubahan kelimpahan relatif spesies karang, menurunkan tutupan karang hidup dan keanekaragaman spesies [3]. Hal ini diperkuat oleh penelitian lainnya, dari hasil penelitian diperoleh bahwa laju sedimentasi berpengaruh negatif terhadap tutupan karang hidup [1]. Penelitian tentang laju sedimentasi pernah dilakukan sebelumnya [7]. Tetapi dalam penelitian tersebut tidak membahas pengaruh arus laut terhadap penyebaran sedimen, sehingga dalam penelitian ini dibahas pengaruh arus laut terhadap penyebaran sedimentasi di Pantai Barane Kabupaten Majene.

\section{METODE}

Pelaksanaan penelitian ini dibagi dalam tiga tahapan utama, terdiri dari pembuaatan alat penangkap sedimen, pengukuran sampel dan analisa data

\subsection{Lokasi Penelitian}

Lokasi penelitian ini tersebar dalam tiga titik lokasi sepanjang Pantai Barane, seperti ditunjukkan pada gambar berikut:

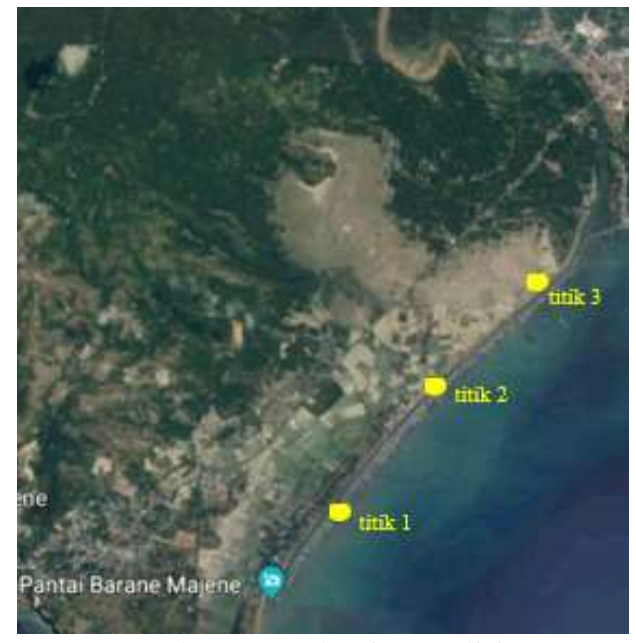

Gambar 1. Lokasi Penelitian

\subsection{Teknik Pengambilan Sampel}

Teknik pengumpulan data dilakukan dengan mengumpulkan data primer dan data sekunder. Data primer yaitu wawancara terhadap masyarakat dan hasil pengukuran laju sedimentasi di lapangan. Sedangkan, data sekunder berupa informasi di kantor desa dan melalui berbagai literatur. Pengukuran sedimen di lapangan dilakukan dengan membagi lokasi penelitian menjadi 3 titik pengukuran sampel seperti yang terlihat pada Gambar 1, 
Dimana Titik 3 merupakan wilayah dekat muara sungai, Titik 2 merupakan wilayah di tengah perairan, dan Titik 1 merupakan wilayah di bagian barat perairan yang agak jauh dari pengaruh muara sungai. Di setiap Titik akan dipasang perangkap sedimen dan diukur laju sedimentasi menggunakan mistar tiap minggu selama 3 minggu. Secara keseluruhan, total pengukuran sampel di lapangan adalah sebanyak 9 kali. Konstruksi perangkap sedimen terdiri atas besi sepanjang $4 \mathrm{~m}$ dan pipa 2 inch sepanjang $25 \mathrm{~cm}$, seperti yang ditunjukkan pada Gambar 2.

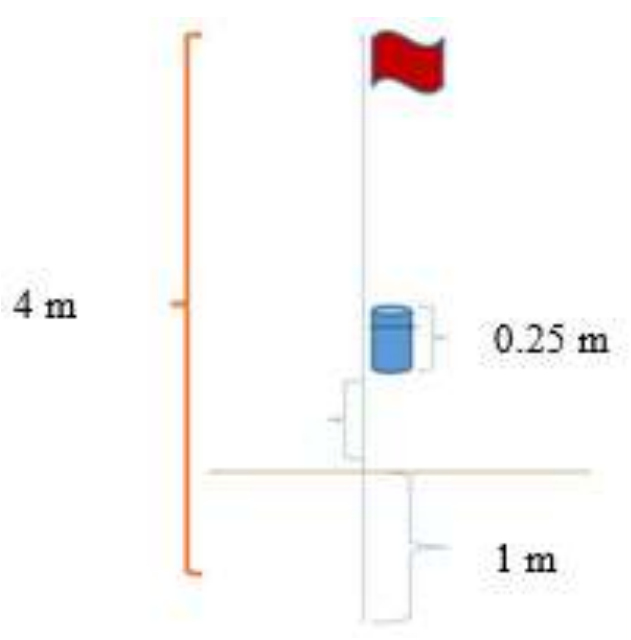

Gambar 2. Alat Penangkap Sedimen

\subsection{Analisis data}

Dalam menghitung laju sedimentasi menggunakan rumus di bawah ini.

$$
v=\frac{\pi r^{2} h}{t}
$$

dimana $\mathrm{v}=$ laju sedimentasi, $\pi=$ konstanta, $\mathrm{r}=$ jari-jari pipa, $\mathrm{h}=$ tinggi sedimen dalam pipa, dan $\mathrm{t}=$ lama waktu (Manoppo, 2014). Kemudian, rata-rata laju sedimentasi dihitung dengan menggunakan metode perhitungan berikut ini.

$$
\bar{x}=\frac{\Sigma \mathrm{xi}}{\mathrm{n}}
$$

dimana $\bar{x}=$ rata - rata, $\mathrm{x}_{\mathrm{i}}=$ suku $\mathrm{ke}-\mathrm{i}$, dan $\mathrm{n}=$ total data [7].

\section{HASIL DAN PEMBAHASAN}

Tabel 1. Hasil Pengukuran Tinggi Sedimen

\begin{tabular}{llllll}
\hline No & Kegiatan & Waktu & Titik 1 & titik 2 & titik 3 \\
\hline 1 & Pembuatan Alat & Selasa, 11 september 2018 & - & - & - \\
2 & Pemasangan Alat & Rabu, 12 September 2018 & - & - & - \\
3 & Pengukuran I & Rabu, 19 September 2018 & $14 \mathrm{~cm}$ & $12 \mathrm{~cm}$ & $16 \mathrm{~cm}$ \\
4 & Pengukuran II & Rabu, 26 September 2018 & $17 \mathrm{~cm}$ & $15 \mathrm{~cm}$ & $13 \mathrm{~cm}$ \\
5 & Pengukuan III & Rabu, 03 Oktober 2018 & $22 \mathrm{~cm}$ & $20.5 \mathrm{~cm}$ & $15.2 \mathrm{~cm}$ \\
\hline
\end{tabular}

Bedasarkan tabel 1, hasil pengukuran tinggi sedimen pada Titik 1 berkisar antara $12-16 \mathrm{~cm}$ dengan rata-rata sebesar $17,7 \mathrm{~cm}$. Titik 2 berkisar antara $13-17 \mathrm{~cm}$ dengan rata - rata sebesar 15,83 cm, dan titik 3 berkisar 15,2-22 cm dengan rata - rata sebesar 14,73 cm. Gambar berikut menunjukkan diagram pengukuran tinggi sedimen. 


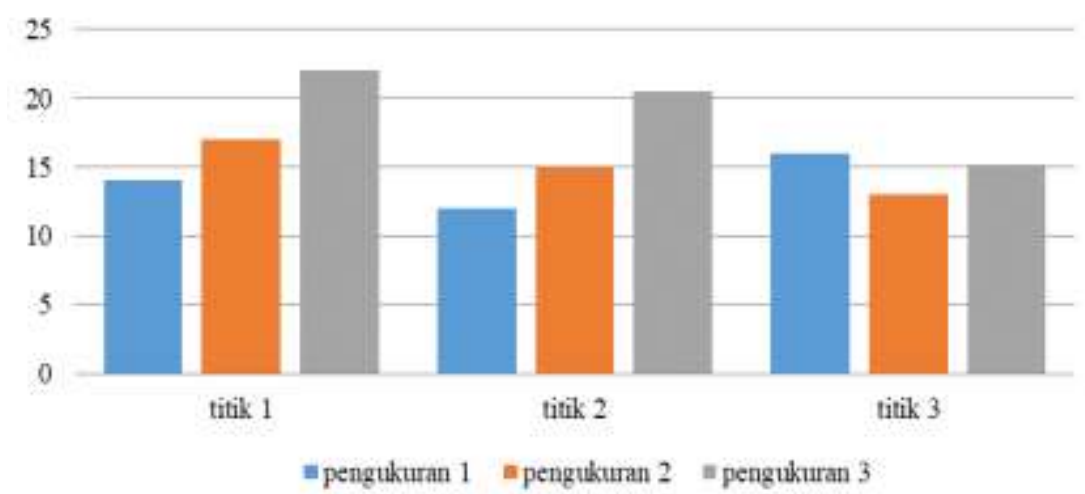

Gambar 3 Diagram Pengukuran Tinggi Sedimen

Hasil pengukuran menunjukkan tinggi sedimen terbesar terletak di titik 1. pada Titik 1 dan 2 terlihat lonjakan nilai sedimen yang semakin besar sedangkan untuk titik 3 adanya penurunan sedimen pada pengukuran ke 2 . Hal ini disebabkan sedimen terbawa arus menuju ke arah Pantai Barane.

Tabel 2. Pengukuran Laju Sedimen di Titik 1

\begin{tabular}{lllll}
\hline Pengukuran & Tinggi $\left(\mathrm{cm}^{3}\right)$ & Volume $\left(\mathrm{cm}^{3}\right)$ & \multicolumn{2}{l}{ Laju sedimentasi } \\
\cline { 4 - 5 } 1 & & & $\left(\mathrm{~cm}^{3} /\right.$ hari $)$ & $\left(\mathrm{cm}^{3} /\right.$ Tahun $)$ \\
2 & 14 & 283.61 & 40.516 & 14788.36 \\
3 & 17 & 344.39 & 49.198 & 17957.29 \\
Rata-rata & 22 & 445.68 & 63.668 & 23238.85 \\
\hline
\end{tabular}

Tabel 3. Pengukuran Laju Sedimen di Titik 2

\begin{tabular}{lllll}
\hline Pengukuran & Tinggi $\left(\mathrm{cm}^{3}\right)$ & Volume $\left(\mathrm{cm}^{3}\right)$ & \multicolumn{2}{l}{ Laju sedimentasi } \\
\cline { 4 - 5 } & & & $\left(\mathrm{cm}^{3} /\right.$ hari $)$ & $\left(\mathrm{cm}^{3} /\right.$ Tahun $)$ \\
2 & 12 & 243.10 & 34.728 & 12675.73 \\
3 & 15 & 303.87 & 43.410 & 1584.670 \\
Rata-rata & 20.5 & 415.29 & 59.327 & 21654.38 \\
\hline
\end{tabular}

Tabel 4. Pengukuran Laju Sedimen di Titik 3

\begin{tabular}{lllll}
\hline Pengukuran & Tinggi $\left(\mathrm{cm}^{3}\right)$ & Volume $\left(\mathrm{cm}^{3}\right)$ & \multicolumn{2}{l}{ Laju sedimentasi } \\
\cline { 3 - 5 } & & & $\left(\mathrm{cm}^{3} /\right.$ hari $)$ & $\left(\mathrm{cm}^{3} /\right.$ Tahun $)$ \\
2 & 16 & 324.13 & 46.304 & 16900.98 \\
3 & 13 & 263.35 & 37.622 & 13732.04 \\
Rata-rata & 15.2 & 307.92 & 43.989 & 16055.93 \\
\hline
\end{tabular}

Berdasarkan hasil perhitungan, laju sedimentasi untuk titik 1 berkisar antara $14788,36-23238.85 \mathrm{~cm}^{3} / \mathrm{tahun}$ dengan rata-rata laju sedimentasi sebesar $18661,5 \mathrm{~cm}^{3} /$ tahun, laju sedimentasi untuk titik 2 berkisar antara $12675.73-21654.38 \mathrm{~cm}^{3} /$ tahun dengan rata-rata laju sedimentasi sebesar $16724.92 \mathrm{~cm}^{3} /$ tahun, dan laju sedimentasi untuk titik 3 berkisar antara $13732.04-16900.98 \mathrm{~cm}^{3} /$ tahun dengan rata-rata laju sedimentasi sebesar $15562.98 \mathrm{~cm}^{3} /$ tahun. Laju sedimentasi paling tinggi di Pantai Barane adalah di titik 1(ujung barat Pantai Barane) sedangkan laju sedimentasi yang pling rendah adalah di titik 3 (dekat muara sungai tinambung) hal ini diakibatkan oleh adanya arus laut yang membawa sedimen dari muara sungai menuju ke Pantai Barane sehingga terjadi penumpukan sedimen di ujung barat Pantai Barane yang berbentuk tanjung. Dampak sederhana dari penumpukan sedimen di Pantai Barane adalah penambahan garis pantai ke arah laut di Pantai Barane. Berikut adalah peta arus laut di sepanjang Pantai Majene. 


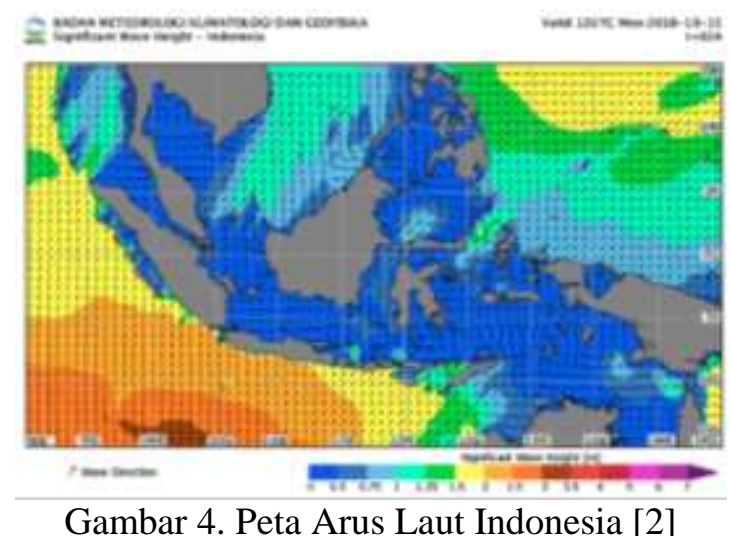

Gambar 4 menunjukkan arah arus laut di indonesia pada bulan oktober. Sulawesi barat khususnya Kabupaten Majene arah arus laut mengarah ke arah utara dan barat disepanjang pesisir pantai majene sehingga membawa sedimentasi ke arah tersebut di sepanjang Pantai Barane. Berikut adalah gambar ujung barat Pantai Barane.

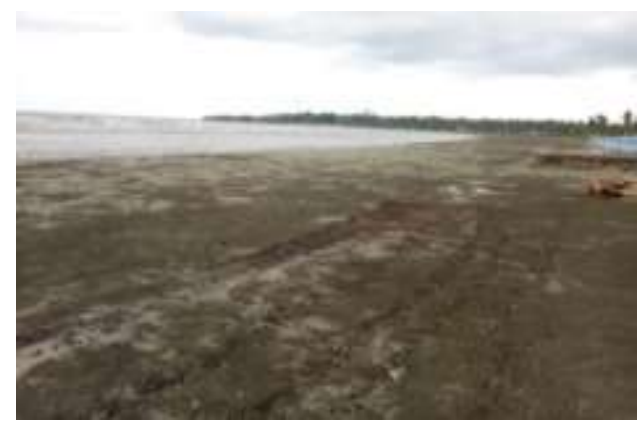

Gambar 5. Ujung Barat Pantai Barane

\section{KESIMPULAN}

Laju sedimentasi pada titik 1 berkisar antara 14788,36 $-23238.85 \mathrm{~cm}^{3} /$ tahun dengan rata-rata laju sedimentasi sebesar $18661,5 \mathrm{~cm}^{3} /$ tahun. Laju sedimentasi untuk titik 2 berkisar antara $12675.73-21654.38 \mathrm{~cm}^{3} /$ tahun dengan rata-rata laju sedimentasi sebesar $16724.92 \mathrm{~cm}^{3} /$ tahun. Laju sedimentasi untuk titik 3 berkisar antara $13732.04-16900.98 \mathrm{~cm}^{3} /$ tahun dengan rata-rata laju sedimentasi sebesar $15562.98 \mathrm{~cm}^{3} /$ tahun. Laju sedimentasi tertinggi terdapat di ujung barat Pantai Barane yaitu pada titik 1. Arus laut membawa sedimen ke arah ujung barat Pantai Barane sehingga laju sedimentasi terbesar terdapat di titik 1.

\section{DAFTAR PUSTAKA}

[1] Adriman 2013 Pengaruh Sedimentasi Terhadap Terumbu Karang di Kawasan Konservasi Laut Daerah Bintan Timur Kepulauan Riau Berkala Perikanan Terubuk, Vol. 41 No. 1 ISSN 0126 - 4265.

[2] CEM 2001 Fundamental of Design US Army Corps of Engineers

[3] Connell, D.W. and D.W. Hawker (Ed) 1992 Pollution in Tropical Aquatic System CRC Press, Inc. London.

[4] Khatib, Anwar 2013 Analisis Sedimentasi dan Alternatif Penanganannya di Pelabuhan Selat Baru Bengkalis. Civil Engineering Department, Universitas Islam Riau, Pekanbaru.

[5] Manoppo and Lefrand 2014 Optimalisasi Pengelolaan Sumberdaya Ikan Selar (Selaroides Leptolepis) Melalui Penguatan Kearifan Lokal Melombo di desa Salurang Kabupaten Kepulauan Sangihe Universitas Brawijaya Malang

[6] Staford, M.G and Smith 1993 Mortality of the hard coral leptoria phyrigia under presistent sediment influx Proceedings of the $7^{\text {th }}$ International Coral Symposium, Guam. Volume 1: 289-299

[7] Supangat 2014 Perhitungan Sedimen. Balai Penelitian Teknologi Kehutanan Pengelolaan DAS, Surakarta

[8] Triatmodjo B 1999 Teknik Pantai Beta Offset Yogyakarta.

copyright is published under Lisensi Creative Commons Atribusi 4.0 Internasional. 